PMW structure (Baldinozzi, Sciau, Buffat \& Stadelmann, 1994).

\section{References}

Baldinozzi, G., Sciau, Ph. \& Buffat, P.-A. (1993). Solid State Commun. 86, 541-544.

Baldinozzi, G., Sciau, Ph., Buffat, P.-A. \& Stadelmann, P.-A. (1994). Electron Microscopy ICEM 13 Paris (Les Editions de Physique, Les Ulis), Vol. 1, pp. 875-876.

Baldinozzi, G., Sciau, PH. \& Lapasset, J. (1992). Phys. Status Solidus $A, 133,17-23$.

BÉRAR, J.-F. \& GARNIER, P. (1992), APD 2nd Conference NIST, May 1992, Gaithersburg, Maryland, USA.

Boher, P., Garnier, P., Gavarr, J. R. \& Hewat, A. W. (1985). J. Solid State Chem. 57, 343-350.

Choo, W. K., KIM, H. J., Yang, J. H., LiM, H., LeE, J. Y., Kwon, J. R. \& Chun, C. H. (1993). Jpn. J. Appl. Phys. 32, 4249-4253.
Funshita, H. \& Hoshino, S. (1984). J. Phys. Soc. Jpn, 53, 226-234.

FuJShITA, H., ShIOZaKı, Y., ACHIWa, N. \& SaWaguchi, E. (1982). J. Phys. Soc. Jpn, 51, 3583-3591.

Galasso, F. S. (1990). Perovskites and High $T_{c}$ Superconductors. New York: Gordon and Breach.

Glazer, A. M (1972). Acta Cryst. B28, 3384-3392.

Glazer, A. M (1975). Acta Cryst. A31, 756-762.

Glazer, A. M., Roleder, K. \& Dec, J. (1993). Acta Cryst. B49, 846-852.

Itoh, K., Zeng, L. Z., NaKamuRa, E. \& Mishima, N. (1985). Ferroelectrics, 63, 29-37.

LEE, M. H. \& CHOO, W. K. (1981). J. Appl. Phys. 52, 5767-5773.

Smolenskil, G. A., Krainik, N. N. \& Agranovskaya, A. I. (1961). Fiz. Tverd. Tela, 3, 981-990 (Sov. Phys. Solid State, 3, 714-720).

Tokmyanina, T. B., Razumovskaya, O. N. \& Belyaev, I. N. (1976). Izv. Akad. Nauk SSSR Neorg. Mater. 12, 2099-2100.

Uchino, K. \& Nomura, S. (1976). J. Phys. Soc. Jpn, 41, 542-547.

Verbaere, A., Piffard, Y., Ye, Z. G. \& Husson, E. (1992). Mater. Res. Bull. 27, 1227-1234.

Acta Cryst. (1995). B51, 673-680

\title{
Structure of $\mathrm{Na}_{3} \mathrm{YSi}_{6} \mathrm{O}_{15}$ - a Unique Silicate Based on Discrete $\mathrm{Si}_{6} \mathrm{O}_{15}$ Units, and a Possible Fast-Ion Conductor
}

\author{
BY S. M. HAILE* AND J. MAIER \\ Max-Planck-Institute für Festkörperforschung, D-70569 Stuttgart, Germany \\ B. J. WUENSCH \\ Department of Materials Science and Engineering, Massachusetts Institute of Technology, Cambridge, \\ MA 02139-4307, USA \\ AND R. A. LAUDISE \\ AT\&T Bell Laboratories, Murray Hill, NJ 07974-0636, USA
}

(Received 25 July 1994; accepted 5 December 1994)

\begin{abstract}
Hydrothermal investigations in the high silica region of the $\mathrm{Na}_{2} \mathrm{O}-\mathrm{Y}_{2} \mathrm{O}_{3}-\mathrm{Si}_{6} \mathrm{O}_{15}$ system, carried out in a search for novel fast-ion conductors (FIC's), yielded the new compound trisodium yttrium hexasilicate, $\mathrm{Na}_{3} \mathrm{YSi}_{6} \mathrm{O}_{15}$. Single-crystal X-ray methods revealed that $\mathrm{Na}_{3} \mathrm{YSi}_{6} \mathrm{O}_{15}$ crystallizes in space group $\mathrm{Ibmm}$, has lattice constants $a=10.468(2), b=15.2467$ (13) and $c=8.3855(6) \AA$, $Z=4$, and 11 atoms in the asymmetric unit. Refinement was carried out to a weighted residual of $3.53 \%$ using anisotropic temperature factors for all atoms. The structure is unique in that the silica tetrahedra form isolated $\mathrm{Si}_{6} \mathrm{O}_{15}{ }^{6-}$ double dreier-rings, rather than layers as might be expected from the $\mathrm{Si}$ to $\mathrm{O}$ ratio of 0.4. No isomorphs to $\mathrm{Na}_{3} \mathrm{YSi}_{6} \mathrm{O}_{15}$ have been reported.
\end{abstract}

\footnotetext{
* Author to whom correspondence should be addressed. Presently at: University of Washington, Department of Materials Science and Engineering, Seattle, WA 98102, USA.
}

High ionic conductivity has been observed in a number of alkali silicates. These include $\mathrm{Na}_{5} \mathrm{YSi}_{4} \mathrm{O}_{12}$ (Shannon, Taylor, Gier, Chen \& Berzins, 1978), $\mathrm{Na}_{2} \mathrm{ZnSiO}_{4}$ (Frostäng, Grins \& Nygren, 1988), and the solid solution series $\mathrm{Na}_{1+x} \mathrm{Zr}_{2} \mathrm{Si}_{x} \mathrm{P}_{3-x} \mathrm{O}_{12}$ [NASICON (Goodenough, Hong \& Kafalas, 1976)]. In such materials, the alkali ion typically migrates via channels present in the silicate framework. The transport properties of alkali silicates are amenable to crystal-chemical tailoring because both the tunnel geometry and the size of the mobile ion can be altered via substitutions on the non-Si cation sites. Additionally, as with other ionic materials, the concentration of ionic defects can be modified via aliovalent substitutions, with the prospect of increasing the ionic conductivity. We were especially interested in $\mathrm{Na}_{3} \mathrm{YSi}_{6} \mathrm{O}_{15}$ for a number of reasons. Firstly, we previously measured the conductivity of $\mathrm{K}_{3} \mathrm{NdSi}_{6} \mathrm{O}_{15}$ (Haile, Wuensch, Siegrist \& Laudise, 1992) and found 
it to have a reasonably high conductivity for a material in which $\mathrm{K}^{+}$is the mobile species. Secondly, Watanabe \& Wuensch (1993) reported a rather high conductivity for $\mathrm{Na}_{3} \mathrm{YSi}_{6} \mathrm{O}_{15}$ glass. These two observations suggested that the crystalline sodium analog to $\mathrm{K}_{3} \mathrm{NdSi}_{6} \mathrm{O}_{15}$, having a smaller and typically more mobile species as the charge carrier, might exhibit fast-ion conduction. In addition, the anisotropy we observed in the properties of $\mathrm{K}_{3} \mathrm{NdSi}_{6} \mathrm{O}_{15}$ suggested this class of compounds to be ideal for correlating structural features to observed conductivities.

\section{Experimental}

\section{Crystal growth}

Crystals of $\mathrm{Na}_{3} \mathrm{YSi}_{6} \mathrm{O}_{15}$ were grown by the hydrothermal method, as described elsewhere (Haile, Wuensch \& Laudise, 1993). This technique, which employs high temperatures and pressures to dissolve a normally insoluble precursor and precipitate the desired crystalline phase, has been utilized because of its effectiveness in inducing crystallization in glassforming systems (Laudise, 1987). Typically, $0.05 \mathrm{~g}$ of a glass nutrient of composition $4 \mathrm{Na}_{2} \mathrm{O}-\mathrm{Y}_{2} \mathrm{O}_{3}-17 \mathrm{SiO}_{2}$ was placed in sealed cylindrical platinum capsules, $0.40 \mathrm{~cm}$ in diameter and $2.3-2.7 \mathrm{~cm}$ in length, with a total volume of $0.200-0.250 \mathrm{~cm}^{3}$ (after accounting for the loss in volume to the sealing process). These were, in turn, placed in Tuttle autoclaves (Tuttle, 1949), the design of which allowed the pressure to be controlled explicitly by the use of an intensifier, gauge and valve system. The pressure was held at either 825 or $1400 \times$ $10^{5} \mathrm{~Pa}$, the temperature at 773,823 or $873 \mathrm{~K}$, and the solvent was either pure water or a dilute solution of a sodium base $\left(0.1 \mathrm{M} \mathrm{NaOH}, \mathrm{Na}_{2} \mathrm{CO}_{3}\right.$ or $\left.\mathrm{NaHF}_{2}\right)$. After 7-12 d experiments yielded a crystalline powder of $\mathrm{Na}_{3} \mathrm{YSi}_{6} \mathrm{O}_{15}$ with a crystallite size of several microns.

\section{Composition determination}

The composition was determined both from electron microprobe measurements and by inductively coupled plasma (ICP) spectroscopy. Microprobe measurements were performed on small crystals that had been mounted in an epoxy resin, polished and then sputter-coated using a gold/palladium electrode. Data were collected on a Jeol Superprobe 733 equipped with a wavelength dispersive detector. The intensities of the characteristic X-radiation peaks were converted to stoichiometric quantities using the ZAF data reduction program (Schamber, Wodke \& McCarthy, 1981). The following materials were employed as standards: $\mathrm{SiO}_{2}$ quartz glass, a single crystal of yttrium aluminum garnet, and sodalite or amelia albite glass for $\mathrm{Na}$. These measurements yielded mole percentages of $\mathrm{Na}, \mathrm{Y}$ and $\mathrm{Si}$ of 12.1(3), 4.0(3) and $24.6(8)$, respectively, values which are within experi- mental error of those for ideal $\mathrm{Na}_{3} \mathrm{YSi}_{6} \mathrm{O}_{15}: 12,4$ and 24 , respectively. Upon conversion of the experimental values to the weight percentages of the respective oxides, the sum of 101 (2) wt\% was found, indicating that no water of crystallization was present.

ICP spectroscopy was performed after dissolution in a mixture of concentrated $\mathrm{HCl}$ and concentrated $\mathrm{HF}$ at $423 \mathrm{~K}$. Measurements made on a sample of approximately $30 \mathrm{mg}$ yielded $\mathrm{Na}, \mathrm{Y}, \mathrm{Si}$ and $\mathrm{O}$ weight percentages of $11.9,13.9,23.7$ and $41.3 \mathrm{wt} \%$, which, when normalized to $13.1,15.3,26.1$ and $45.5 \mathrm{wt} \%$, are comparable to the ideal values of 12.2, 15.7, 29.7 and $42.4 \mathrm{wt} \%$, respectively. We attribute the deviation from $100 \mathrm{wt} \%$ to the small sample size.

\section{Structure determination}

A crystal measuring $0.02 \times 0.06 \times 0.1 \mathrm{~mm}^{3}$ was selected from the product of an experiment conducted at a temperature of $823 \mathrm{~K}$, a pressure of $825 \times 10^{5} \mathrm{~Pa}$, in a $0.1 \mathrm{M} \mathrm{NaOH}$ solution for $12 \mathrm{~d}$. Single-crystal intensity data were collected using a Siemens diffractometer and Mo $K \alpha$ radiation $(\lambda=0.71073 \AA)$. Refinement of the lattice parameters using data for the positions of 82 peaks revealed $\mathrm{Na}_{3} \mathrm{YSi}_{6} \mathrm{O}_{15}$ to be orthorhombic with lattice constants $a=10.468(2), b=15.2467$ (13) and $c=8.3855$ (6) $\AA$. With four formula units per unit cell, $\mathrm{Na}_{3} \mathrm{YSi}_{6} \mathrm{O}_{15}$ has a calculated density of $2.811 \mathrm{~g} \mathrm{~cm}^{-3}$. Intensity data were collected using the $\omega-2 \theta$ scan method, over $2 \theta$ values from 3 to $80^{\circ}$. The measured intensities were corrected for absorption; transmission factors ranged from 0.0334 to 0.0841 . Of 2257 independent intensities, 1418 were considered significant (net intensity greater than three standard deviations). An analysis of the systematic absences showed the diffraction symbol to be $\mathrm{mmm} I(b c)^{* *}$, allowing space groups $I b m m$ and $I c 2 m$ (the latter in two possible orientations). The value of $E^{2}-1,0.863$, gave slight preference to the centrosymmetric group, and thus $1 \mathrm{bmm}$ was employed for the initial calculations and later proven to be correct, as discussed below. The structure was solved by first locating the $Y$ atoms from a Patterson map, and the remaining atoms from successive Fourier-difference maps. All calculations were performed using the SHELXS package of programs (Sheldrick, 1985). The final weighted residuals, after employing anisotropic thermal parameters for all atoms, were 3.57 and $4.11 \%$, for the limited and complete data sets, respectively, for a weighting scheme defined by $w=3.2117 \sigma(F)^{-2}$. Nonweighted residuals were 8.24 and $12.13 \%$. A list of $F_{\text {obs }}$ and $F_{\text {calc }}$ is provided. After the last cycle of refinement, the deepest hole in the Fourier-difference map was $2.407 \mathrm{e} \AA^{-3}$, and the highest peak $3.910 \mathrm{e} \AA^{-3}$. No correlation terms in the least-squares matrix were greater than 0.5 .

The atomic coordinates and thermal parameters for the 11 atoms in the asymmetric unit are reported in Table 1 . The second $\mathrm{Na}$ atom, $\mathrm{Na}(2)$, has an occupancy 
Table 1. Atomic coordinates and thermal parameters of $\mathrm{Na}_{3} \mathrm{YSi}_{6} \mathrm{O}_{15}$ (e.s.d.'s given in parentheses)

The anisotropic temperature factors are of the form $\exp \left[-2 \pi^{2}\left(h^{2} u_{27} a^{* 2}+\ldots+h k u_{12} a^{*} b^{*}+\ldots\right)\right]$ and are given in units of $10^{-2} \AA^{2}$. The compound crystallizes in space group $I b m m$, and has lattice constants $a=10.468(2), b=15.2467(13)$ and $c=8.3855(6) \AA$.

\begin{tabular}{|c|c|c|c|c|c|c|c|c|c|c|}
\hline $\mathrm{Y}$ & $\begin{array}{l}\text { Position } \\
4 c . .2 / m\end{array}$ & $1 / 4^{x}$ & $1 / 4$ & $1 / 4^{z}$ & $\begin{array}{c}U_{11} \\
1.147(18)\end{array}$ & $\begin{array}{c}U_{22} \\
1.068(17)\end{array}$ & $\begin{array}{c}U_{33} \\
1.068(19)\end{array}$ & $\begin{array}{c}U_{12} \\
1.126(19)\end{array}$ & $0^{U_{13}}$ & $0^{U_{23}}$ \\
\hline $\mathrm{Si}(1)$ & $8 i . . m$ & $-0.03353(8)$ & $0.40244(6)$ & $1 / 4$ & $1.18(4)$ & $1.19(4)$ & $1.34(4)$ & $0.10(3)$ & 0 & 0 \\
\hline $\mathrm{Si}(2)$ & $16 \mathrm{~J} 1$ & $-0.28438(6)$ & 0.40016 (5) & $0.42866(8)$ & $1.25(3)$ & $1.29(3)$ & $1.22(3)$ & $0.02(2)$ & $0.04(2)$ & $0.15(2)$ \\
\hline $\mathrm{Na}(1)$ & $8 f .2$ & $1 / 2$ & $0.24005(9)$ & 0 & $2.15(7)$ & $1.85(9)$ & $2.16(8)$ & 0 & $0.62(6)$ & 0 \\
\hline $\mathrm{Na}(2)$ & $8 i . . m$ & $0.4227(4)$ & $0.4606(3)$ & $1 / 4$ & $3.57(20)$ & $5.20(25)$ & $2.46(19)$ & $0.17(18)$ & 0 & 0 \\
\hline $\mathrm{O}(1)$ & $8 i . . m$ & $0.3481(2)$ & $0.38768(18)$ & $3 / 4$ & $1.30(11)$ & 2.28 (14) & $1.46(12)$ & $-0.02(10)$ & 0 & 0 \\
\hline $\mathrm{O}(2)$ & $8 i . . m$ & $0.4338(2)$ & $0.17522(16)$ & $1 / 4$ & $1.37(11)$ & $1.41(11)$ & $1.62(12)$ & $0.23(9)$ & 0 & 0 \\
\hline$O(3)$ & $16 j \quad 1$ & $0.62972(15)$ & $0.10678(12)$ & $0.0952(2)$ & $1.27(7)$ & $1.96(8)$ & $1.45(8)$ & $0.10(7)$ & $0.09(5)$ & $0.08(7)$ \\
\hline $\mathrm{O}(4)$ & $8 h . m$. & $0.3210(2)$ & $1 / 2$ & $-0.0135(3)$ & $1.82(13)$ & $1.46(12)$ & $1.98(13)$ & 0 & $-0.40(10)$ & 0 \\
\hline $\mathrm{O}(5)$ & $16 j \quad 1$ & $0.16320(17)$ & $0.16573(13)$ & $0.0573(2)$ & $1.70(8)$ & $2.15(9)$ & $1.76(9)$ & $0.28(7)$ & $-0.15(7)$ & $-0.77(7)$ \\
\hline $\mathrm{O}(6)$ & $4 e 2 \mathrm{~mm}$ & $0.4715(3)$ & 0 & $1 / 4$ & $1.54(16)$ & $1.12(15)$ & $2.13(19)$ & 0 & 0 & 0 \\
\hline
\end{tabular}

of 0.5 , and four $\mathrm{Na}$ atoms per unit cell are distributed over the eight equivalent sites of $8 i$. This leads to a rather small $\mathrm{Na}-\mathrm{Na}$ separation of $1.201 \AA$. The proximity of these sites to the special position, $4 e\left(x, \frac{1}{2}, \frac{1}{4}\right)$ with $x=0.4227(4)$, suggested that $\mathrm{Na}(2)$ might fully occupy a single site on one or the other side of the high symmetry position, thereby lowering the space group symmetry to $I c 2 m$. A Fourier difference map in the space group of lower symmetry, however, showed two equally significant peaks at the positions related by pseudosymmetry. Attempts to refine the structure in $I c 2 m$ reduced the residual only nominally, while causing some bond lengths to assume unreasonable values. Additionally, a number of elements in the leastsquares matrix became strongly correlated as a result of the pseudosymmetry. We are thus confident $I \mathrm{lmmm}$ is the true space group.

Bond distances in the cation polyhedra are given in Table 2. Bond lengths to oxygen, oxygen-oxygen separations, and oxygen-cation-oxygen bond angles are tabulated for the $\mathrm{Y}$ and $\mathrm{Si}$ tetrahedra. $\mathrm{O}$ atoms bonded to two Si atoms are designated as 'bridging' (br), whereas 'terminating' (term) indicates those bonded to only one. Silicon-oxygen-silicon angles for the bridging $\mathrm{O}$ atoms are also provided in Table 2 . Only oxygen-cation distances are given for the $\mathrm{Na}$ polyhedra. In addition to the bond distances from the two Na sites that have been refined from $\mathrm{X}$-ray data, the distances from what is considered to be the center of a ten-membered cage in which two $\mathrm{Na}(2)$ sites are located are also included. The nature of this cage is discussed in greater detail below.*

\section{Discussion of the structure}

\section{Nature of the silicate unit}

As can be seen from Table 2, three of the four oxygen atoms on both silica tetrahedra are bridging, while the

\footnotetext{
* A list of structure factors has been deposited with the IUCr (Reference: DU0394). Copies may be obtained through The Managing Editor, International Union of Crystallography, 5 Abbey Square, Chester CH1 $2 \mathrm{HU}$, England.
}

Table 2. Cation coordination polyhedra in $\mathrm{Na}_{3} \mathrm{YSi}_{6} \mathrm{O}_{15}$ with bond distances and angles (e.s.d.'s in parentheses)

Number in parentheses after atom identifies the atom in terms of Table 2. $2 \times, 4 \times$ etc. indicates multiplicity of the bond. Oxygen-oxygen distances and angles are given for the yttrium octahedron and the silicon tetrahedra. $\mathrm{Si}-\mathrm{O}-\mathrm{Si}$ angles are also provided.

\begin{tabular}{|c|c|c|c|c|c|}
\hline $\begin{array}{l}\text { Central } \\
\text { atom }\end{array}$ & Bond dist & ance $(\AA ̊)$ & Oxygen separa & tion $(\AA)$ & $\begin{array}{c}\mathrm{O}-M-\mathrm{O} \\
\text { angle }\left({ }^{\circ}\right)\end{array}$ \\
\hline Y & $O(2) 2 x$ & $2.237(2)$ & $O(2)-O(5) 4 \times$ & 3.265 (3) & $93.22(6)$ \\
\hline & $O(5) 4 x$ & $2.256(2)$ & $O(2)-O(5) 4 \times$ & $3.086(3)$ & $86.78(6)$ \\
\hline & & & $O(2)-O(5) 4 x$ & 3.147 (2) & $88.5(1)$ \\
\hline & & & $O(5)-O(5) 2 \times$ & $3.232(4)$ & $91.5(1)$ \\
\hline & & & $O(5)-O(5) 4 \times$ & 4.511 (4) & 180 \\
\hline & & & $\mathrm{O}(2)-\mathrm{O}$ & $4.473(5)$ & 180 \\
\hline $\mathrm{Si}(1)$ & $\mathrm{O}(2)_{\text {term }}$ & $1.578(3)$ & $O(2)-O$ & $2.700(2)$ & $115.0(2)$ \\
\hline & $\mathrm{O}(6)_{\mathrm{br}}$ & $1.623(2)$ & $O(2)-O$ & $2.642(3)$ & $109.87(9)$ \\
\hline & $\mathrm{O}(3)_{\mathrm{br}} 2 \times$ & $1.648(2)$ & $O(6)-O(3) 2 x$ & $2.661(3)$ & $108.8(1)$ \\
\hline & & & $\mathrm{O}(3)-\mathrm{O}$ & 2.5 & \\
\hline $\mathrm{Si}(2)$ & $\mathrm{O}(5)_{\text {term }}$ & $1.573(2)$ & $O(5)-O$ & $72(2)$ & $112.8(1)$ \\
\hline & $\mathrm{O}(3)_{\mathrm{br}}$ & $1.635(2)$ & $O(5)-$ & $2.601(2)$ & $108.0(1)$ \\
\hline & $\mathrm{O}(4)_{b r}$ & $1.643(1)$ & $O(5)-C$ & $2.705(2)$ & 114.1 (1) \\
\hline & $\mathrm{O}(1)_{b r}$ & $1.651(1)$ & $O(3)-O(4)$ & $2.670(3)$ & $109.1(1)$ \\
\hline & & & $O(3)-O(1)$ & $2.630(3)$ & $106.3(1)$ \\
\hline & & & $O(4)-O(1)$ & $2.635(3)$ & $106.3(1)$ \\
\hline & & & ond-angles, $\mathrm{S}$ & $-\mathrm{Si}\left({ }^{\circ}\right)$ & \\
\hline & 2) $-O(1)-S$ & (2) 130 & $\mathrm{Si}(2)$ & 4) $-\mathrm{Si}(2)$ & $135.8(2)$ \\
\hline & $-\mathrm{O}(3)-\mathrm{S}$ & (1) 134 & $\mathrm{Si}(2)$ & 6) $-\mathrm{Si}(2)$ & $132.8(2)$ \\
\hline $\mathrm{Na}(1)$ dis & stances $(\AA)$ & & $\mathrm{Na}(2) \mathrm{dis}$ & es $(\AA)$ & \\
\hline & $2.283(2)$ & $\mathrm{Na}\left(2^{\prime}\right)$ & $1.201(8)$ & & \\
\hline$O(2) 2 x$ & $2.419(1)$ & $O(4) 2 x$ & $2.525(3)$ & $O\left(4^{\prime}\right) 2 x$ & $3.390(4)$ \\
\hline & $2.571(2)$ & $O(1)$ & $2.644(5)$ & & $3.333(5)$ \\
\hline & & $O(5) 2 x$ & $2.670(4)$ & O(5) $2 x$ & $3.634(4)$ \\
\hline & & & & & \\
\hline & & $O(4) 2 x$ & 2.643 & $O\left(4^{\prime}\right) 2 x$ & 3.035 \\
\hline & & $O(1) 2 x$ & 2.643 & $O(5) 4 \times$ & 3.263 \\
\hline
\end{tabular}

remaining anion is terminating. This bonding scheme is the simplest way in which the silicon-to-oxygen ratio of 0.4 in $\mathrm{Na}_{3} \mathrm{YSi}_{6} \mathrm{O}_{15}$ can be accommodated. Table 2 also reveals that the average $\mathrm{Si}-\mathrm{O}_{\text {term }}$ distance, 1.576 (3) $\AA$, is smaller than the average $\mathrm{Si}-\mathrm{O}_{\mathrm{br}}$ distance, $1.641(11) \AA$, by $0.065 \AA$. This difference, which is significantly larger than the standard deviation, results from the 'lop-sided' potential experienced by the terminal oxygen and agrees well with values encountered in other silicates (Liebau, 1985).

The silica tetrahedra in $\mathrm{Na}_{3} \mathrm{YSi}_{6} \mathrm{O}_{15}$ are linked together to form double dreier-rings having point group 
$2 \mathrm{~mm}$. This discrete species is best described as a short tubular unit, with a circumference consisting of three silicate tetrahedra and a length of two tetrahedra. Alternatively, it can be considered as the unit resulting from the condensation of a pair of three-membered rings such that previously terminal $\mathrm{O}$ atoms are shared at a common interfacial plane. One of these isolated $\mathrm{Si}_{6} \mathrm{O}_{15}{ }^{6-}$ units is depicted in Fig. 1. The vast majority of silicates with a silicon-to-oxygen ratio of 0.4 form layered structures, while others take on various chain and single-ring configurations. Reports of double-ring compounds are few. Only one other phase that contains the double dreier-ring is known (Smolin, 1970). Indeed, the chemical analogs to $\mathrm{Na}_{3} \mathrm{YSi}_{6} \mathrm{O}_{15}-\mathrm{Na}_{3} \mathrm{NdSi}_{6} \mathrm{O}_{15} . x \mathrm{H}_{2} \mathrm{O}$ (Haile, 1992) and $\mathrm{K}_{3} \mathrm{NdSi}_{6} \mathrm{O}_{15}$ (Haile, Siegrist, Laudise \& Wuensch, 1991; Pushcharovskii, Karpov, Pobedimskaya \& Belov, $1977)$ - are both based on single $\left(\mathrm{Si}_{2} \mathrm{O}_{5}\right)$ layers. Other analogs, such as $\mathrm{Na}_{2} \mathrm{LiYSi}_{6} \mathrm{O}_{15}$, take on a double-chain configuration (Gunawardane, Howie \& Glasser, 1982). The structural differences between the $\mathrm{Na}-\mathrm{Y}$ compound and the two Nd compounds are particularly striking as the three phases crystallize under a similar range of hydrothermal conditions (Haile, Wuensch, \& Laudise, 1993; Haile, Wuensch, Siegrist \& Laudise, 1993), with the exception of the slightly higher temperatures required for the synthesis of the Na-Y compound relative to the $\mathrm{Na}-\mathrm{Nd}$ compound.

The rarity of the double dreier-ring results from the small separation between neighboring silicate tetrahedra encountered in this configuration relative to those typically observed in layered structures. A useful measure of the intratetrahedral separation is the distance between neighboring $\mathrm{Si}^{4+}$ ions. This latter quantity, $d(\mathrm{Si}-\mathrm{Si})$, is maximized when the angle defined by $\mathrm{O}-\mathrm{Si}-\mathrm{O}$ takes on a value of $180^{\circ}$. However, because of the partially covalent nature of the $\mathrm{Si}-\mathrm{O}$ bond, this angle typically has a significantly smaller value of approximately $140^{\circ}$. We see from Table 2 that in order to both accommodate the small $\mathrm{Si}-\mathrm{O}-\mathrm{Si}$ angles within the double dreierring unit and maintain as large a $\mathrm{Si}-\mathrm{Si}$ separation as possible, the $\mathrm{Si}-\mathrm{O}$ bond lengths in $\mathrm{Na}_{3} \mathrm{YSi}_{6} \mathrm{O}_{15}$ are unusually long: $1.641(11) \AA$. The $\mathrm{Si}-\mathrm{O}-\mathrm{Si}$ angles, $\mathrm{Si}-\mathrm{Si}$ distances, $\mathrm{Si}-\mathrm{O}_{\mathrm{br}}$ distances and cation properties of the three $M_{3} R \mathrm{Si}_{6} \mathrm{O}_{15}$ synthesized in our laboratory are compared in Table 3. For further comparison, the values for a linear and a bent $\mathrm{Si}_{2} \mathrm{O}_{7}$ double tetrahedra, with ideal bond angles $\left(\mathrm{O}-\mathrm{Si}-\mathrm{O}=109^{\circ}\right)$ and ideal bond lengths $(\mathrm{Si}-\mathrm{O}=1.62 \AA)$, are also included. We notice immediately that smaller $\mathrm{Si}-\mathrm{O}-\mathrm{Si}$ angles do, in fact, correspond to smaller $\mathrm{Si}-\mathrm{Si}$ separations. In the layered compounds, the distances take on a greater range of values, but are, on average, larger than in $\mathrm{Na}_{3} \mathrm{YSi}_{6} \mathrm{O}_{15}$. We also note that, despite the sizable difference in the radii of $\mathrm{K}$ and $\mathrm{Na}$, both neodymium compounds form layered structures. We would thus not expect the difference in ionic radii between $\mathrm{Nd}$ and $\mathrm{Y}$ to explain the great differences between the two sodium compounds. Indeed, we can certainly imagine a layered compound in which the smaller ionic radius of $\mathrm{Y}$ is accommodated, even if it is not isostructural with either of the Nd phases.

For a plausible explanation of the structural differences, we look to the remaining significant chemical difference between $\mathrm{Y}$ and $\mathrm{Nd}$ : the electronegativity. Liebau (1985) has suggested that the electronegativity of a guest cation in a silicate can greatly influence the topology that is assumed by a structure by determining

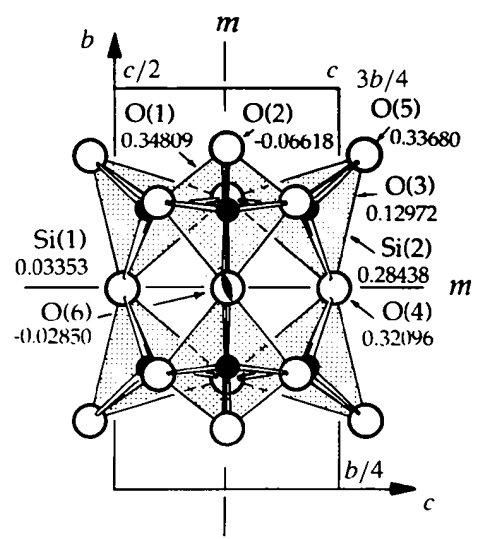

(a)

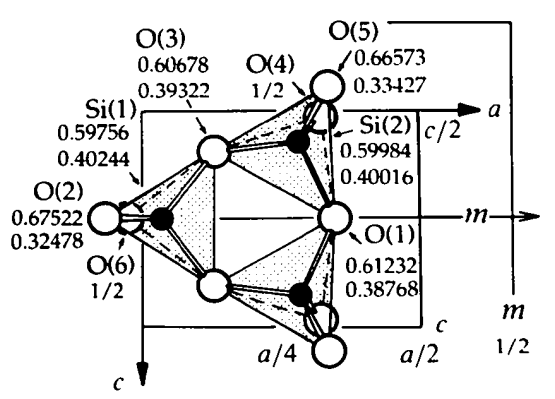

(b)

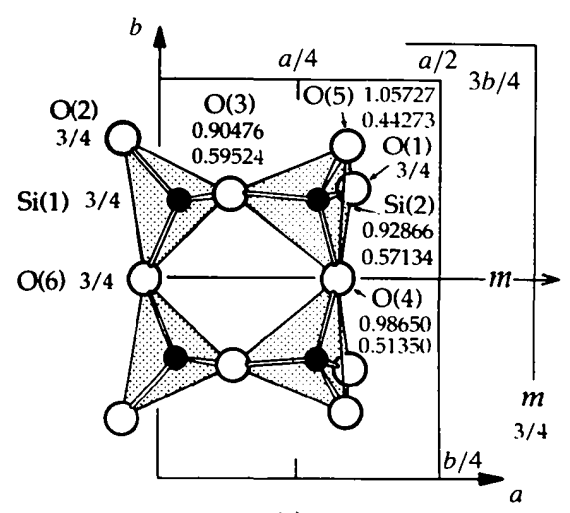

(c)

Fig. 1. The isolated $\mathrm{Si}_{6} \mathrm{O}_{15}{ }^{6-}$ double dreier-ring with point group $2 \mathrm{~mm}$, which is found in $\mathrm{Na}_{3} \mathrm{YSi}_{6} \mathrm{O}_{15}$. The unit that is depicted is on the symmetry line $\left(x, \frac{1}{2}, \frac{3}{4}\right)$ with the drier rings centered at $x \sim 0.200$. (a) Projection along b; (b) projection along $\mathbf{a} ;(c)$ projection along $\mathbf{c}$. 
Table 3. Comparison of structural parameters in three $A_{3} \mathrm{MeSi}_{6} \mathrm{O}_{15}$ compounds and an ideal $\mathrm{Si}_{2} \mathrm{O}_{7}$ double tetrahedra in two configurations (ionic radii listed are those of Shannon \& Prewitt, 1969)

\begin{tabular}{|c|c|c|c|c|c|}
\hline \multirow[b]{2}{*}{ Structure } & \multicolumn{2}{|c|}{ 'Ideal' $\mathrm{Si}_{2} \mathrm{O}_{7}$} & \multirow{2}{*}{$\begin{array}{l}\mathrm{Na}_{3} \mathrm{YSi}_{6} \mathrm{O}_{15} \\
\text { Double ring }\end{array}$} & \multicolumn{2}{|c|}{$\begin{array}{c}\mathrm{Na}_{3} \mathrm{NdSi}_{6} \mathrm{O}_{15} \cdot \mathrm{K}_{3} \mathrm{NdSi}_{6} \mathrm{O}_{15} . \\
x \mathrm{H}_{2} \mathrm{O}\end{array}$} \\
\hline & Linear & Bent & & Layered & Layered \\
\hline $\mathrm{Si}-\mathrm{O}-\mathrm{Si}\left({ }^{\circ}\right)$ & 180 & 140 & $133(2)$ & $142(6)$ & $145(8)$ \\
\hline$d(\mathrm{Si}-\mathrm{Si})(\AA)$ & 3.24 & 3.08 & $3.02(2)$ & $3.08(5)$ & $3.08(7)$ \\
\hline$d\left(\mathrm{Si}-\mathrm{O}_{\mathrm{br}}\right)(\AA)$ & 1.62 & 1.62 & $1.641(11)$ & $1.628(14)$ & $1.620(10)$ \\
\hline $3+$ cation & - & - & $\mathrm{Y}$ & $\mathrm{Nd}$ & Nd \\
\hline $\begin{array}{l}\text { Coordination } \\
\text { number }\end{array}$ & - & - & 6 & 7 & 6 \\
\hline Ionic radius $(\AA)$ & - & - & 0.900 & $\sim 0.99$ & 0.983 \\
\hline Electronegativity & - & - & 1.22 & 1.14 & 1.14 \\
\hline $1+$ cation & - & - & $\mathrm{Na}$ & $\mathrm{Na}$ & $\mathrm{K}$ \\
\hline $\begin{array}{l}\text { Coordination } \\
\text { number }\end{array}$ & - & - & 5,6 & 4,5 & 6,7 \\
\hline Ionic radius $(\AA)$ & - & - & $1.00,1.02$ & $0.99,1.00$ & $1.38,1.46$ \\
\hline Electronegativity & - & - & 0.93 & 0.93 & 0.82 \\
\hline
\end{tabular}

the effective charge of the silicate anionic framework. In the limit of purely ionic bonding between the silicate anion and the guest cation, the effective charge per silicate tetrahedron in an ideal phyllosilicate (three bridging $\mathrm{O}$ atoms and one terminating per $\mathrm{Si}$ ) is -1 . As the electronegativity of the incorporated cation(s) increases, however, the effective charge per silicate tetrahedra decreases. Consequently, maintenance of a large spatial separation between $\mathrm{SiO}_{4}{ }^{-(1-\delta)}$ tetrahedra becomes less important. Liebau has further suggested that when isovalent cations are incorporated into a silicate, the electronegativity of the cation has, in fact, a greater impact on the structure of the silicate anion than the ionic size of the cation. It is thus plausible that the greater electronegativity of Y (1.22) over Nd (1.14) facilitates the formation of the double dreier-ring by decreasing the effective charge per silicate tetrahedra, thereby reducing repulsive coulombic interactions and permitting covalent bonding considerations to dominate. It is of interest to note that the single heretofore reported compound

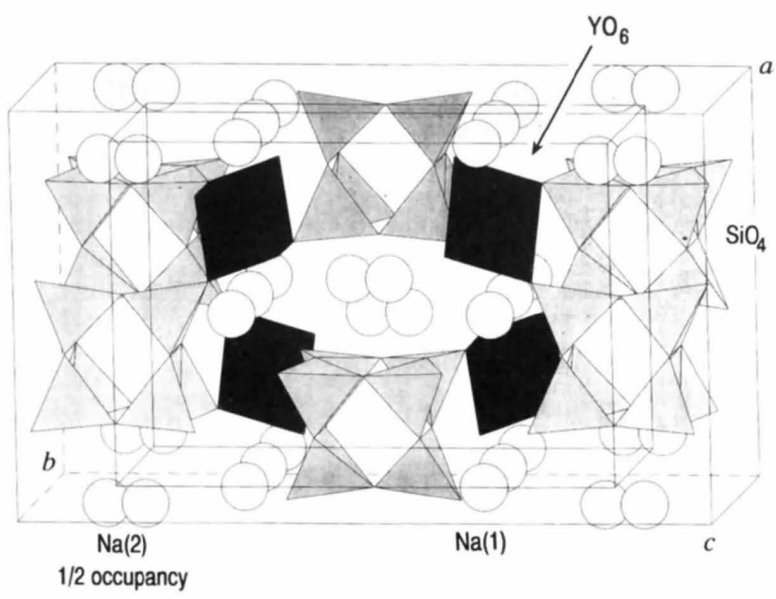

Fig. 2. Structure of $\mathrm{Na}_{3} \mathrm{YSi}_{6} \mathrm{O}_{15}$ viewed along $\mathrm{c}$ using the ATOMS program from Shape Software. The $\mathrm{SiO}_{4}$ and $\mathrm{YO}_{6}$ units are represented as polyhedra. The contents of two cells along $\mathbf{c}$ are depicted. that contains a double dreier-ring is an organosilicate: $\left[\mathrm{Ni}\left(\mathrm{H}_{2} \mathrm{NCH}_{2} \mathrm{CH}_{2} \mathrm{NH}_{2}\right)_{3}\right]_{3}\left[\mathrm{Si}_{6} \mathrm{O}_{15}\right] \cdot \mathrm{H}_{2} \mathrm{O}$ (Smolin, 1970), a compound in which we would expect the 'cation' not to be particularly electropositive.

Turning from the origin of the structure to its topology, a view of the structure along c, Fig. 2, shows that the $\left(\mathrm{YO}_{6}\right)$ octahedra link the isolated $\mathrm{Si}_{6} \mathrm{O}_{15}$ units together to form a three-dimensional framework. Each apex of a particular yttrium octahedron is connected to a different silica unit. These octahedra are rather regular, with the three transpolyhedral angles precisely equal to $180^{\circ}$ (consistent with the $. .2 / m$ site symmetry for Y). The remaining 12 bond angles do not differ from orthogonality by more than $3.5^{\circ}$. Additionally, all $\mathrm{O}$ atoms participating in yttrium octahedra are bonded to only one $\mathrm{Si}$ atom (i.e. are terminating), as one might expect a priori for charge-balance reasons.

\section{Sodium polyhedra: configuration, linkage and possible conduction paths}

One of several criteria necessary for high ionic conductivity in a compound is the presence of pathways through which the mobile species can readily migrate. A second criteria for high ionic conduction is that the pathways for ion migration connect energetically equivalent sites that are present in numbers greater than the number of cations available to fill them. Fig. 2 reveals that the silica-yttria framework defines a set of large tunnels that extend along c. These are ellipsoidal in cross-section, measuring approximately $3.75 \AA$ along a, and extending $11.99 \AA$ in the direction of $\mathbf{b}$.

Both the independent $\mathrm{Na}^{+}$ions are situated within these tunnels. Fig. 3 presents a projection of the contents of the channel along $\mathbf{a}$, the direction of its shortest axis. As can be seen from Fig. 3, two $\mathrm{Na}(2)$ sites are located within a cage defined by ten oxygen ions. The tencornered cage is centered at $4 e 2 \mathrm{~mm}\left(x, \frac{1}{2}\right.$, $\left.\frac{1}{4}\right)$, with $x \approx 0.4596$. Of the ten anions that form the cage, four oxygen ions are located at a distance of $2.643 \AA$, two are at $3.035 \AA$, and another four are $3.226 \AA$ from its center, Table 3. Tenfold coordination is rare for sodium and unfavorable here as well. Six of the interatomic distances from the center to the oxygen anions are much too large even for a ninefold-coordinated sodium ion with an ionic radius of $1.32 \AA\left[R_{\mathrm{O}^{2-}}{ }^{[3]}=1.36 \AA\right.$ (Shannon \& Prewitt, 1969)]. The $\mathrm{Na}^{+}$accordingly pulls off to either side and slightly towards $\mathrm{O}(4)$, Fig. 4. There, it can acquire five neighbors at comparable distances of $2.525-2.670 \AA$, while another five second-nearest neighbors are located at distances of 3.333-3.634 $\AA$. Taken as a single group, the 'coordination polyhedron' formed by the five nearest oxygen neighbors has a rather remarkable configuration. The $\mathrm{Na}(2)$ site is almost coplanar with the triangle defined by $\mathrm{O}(1)$ and a pair of $\mathrm{O}(4)$ ions and, in fact, barely within the polyhedron; the plane defined by $\mathrm{Na}(2)$ and the remaining pair of 
nearest neighbors, $\mathrm{O}(5)$, is close to being normal to the preceding triangle of neighbors. The two $\mathrm{Na}(2)$ sites within the cage are separated only in the $b$ direction and by only $1.2 \AA$. The proximity suggests they are too close to be simultaneously occupied. The coordination about the saddle-point at the center of the cage suggests that the ion hops rather easily between the sites.

The alkali ion designated $\mathrm{Na}(1)$ (also located in the tunnel) sits within a distorted octahedron formed by six neighboring oxygen ions at distances that range from 2.283 to $2.571 \AA$, Fig. 3 . These polyhedra share $\mathrm{O}(2)$ corners to build chains extending along $\mathbf{c}$ and situated at either side of the tunnel. The $\mathrm{Na}(2)$ cages are also joined into chains along $\mathbf{c}$, in this case, through sharing of the $\mathrm{O}(4)-\mathrm{O}\left(4^{\prime}\right)$ edge, which is oriented approximately along $\mathbf{a}$. These two chains of polyhedra are connected to each other via the $\mathrm{O}(5)$ atoms: the $\mathrm{O}(5)-\mathrm{O}\left(5^{\prime}\right)$ edge of the $\mathrm{Na}(2)$ cage joins the corners of two $\mathrm{Na}(1)$ octahedra along c. Face-sharing is a mode of polyhedral linkage that would be more conducive to a pathway of high mobility than the corner- and edge-sharing exhibited, respectively, by the $\mathrm{Na}(1)$ and $\mathrm{Na}(2)$ polyhedra. However, the spaciousness of the channels depicted in Fig. 2 suggests that there are many local minima in which a cation migrating through the structure might temporarily reside, rather than jumping directly between normal sites. Two such potential sites have been identified in Fig. 3 and their nearest neighbors are provided in Table 4 . In fact, the presence of such sites suggests that $\mathrm{Na}_{3} \mathrm{Si}_{6} \mathrm{O}_{15}$ will be an intrinsic fast-ion conductor - a material in which the structure contains vacant sites easily accessible to a jumping ion without the introduction of aliovalent dopant ions.

Fig. 3 reveals that the first site, at $8 i m(0.54,0.28$, $\left.\frac{1}{2}\right)$, might be easily accessible to a cation jumping from one $\mathrm{Na}(1)$ site to another via the rather open sides of the distorted octahedra. The distance from the proposed interstitial site to the two closest $\mathrm{O}$ atoms,

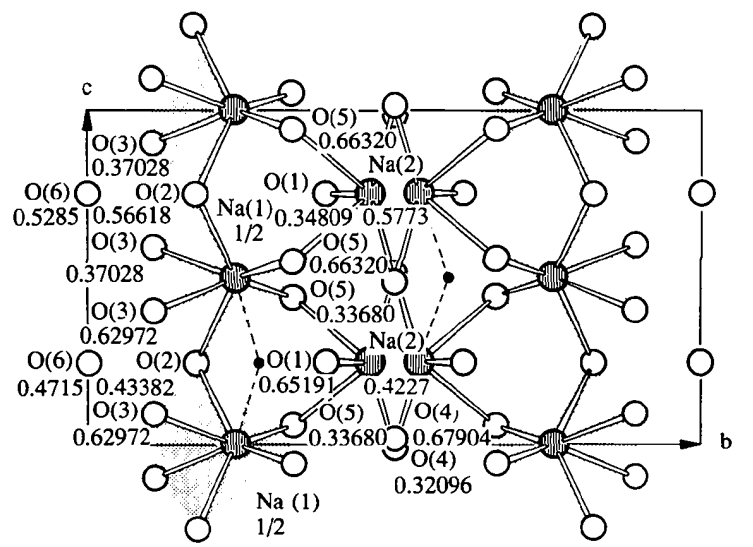

Fig. 3. Projection along a, showing the contents of the tunnel, Na polyhedra, connectivity and the possible interstitial site along the $\mathrm{Na}(1)-\mathrm{Na}(1)$ jump.
$\mathrm{O}(1)$ and $\mathrm{O}(2)$, is $1.98 \AA$, a value not too much less than the expected interatomic distance between $\mathrm{Na}^{+}$and $\mathrm{O}^{2-}$ of $2.35 \AA$, when the ions are four- and threefold coordinated, respectively (Shannon \& Prewitt, 1969). In fact, the coordination about this site, by four more $O$ atoms at distances of less than $3 \AA$, suggests that it should not be too much higher in energy than the normal sites.

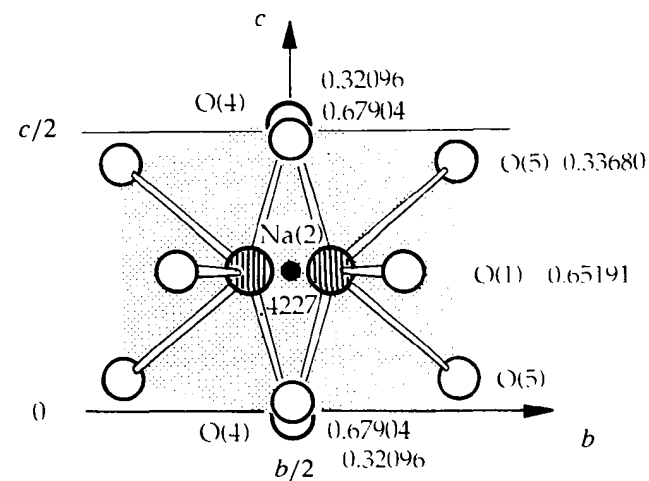

(a)

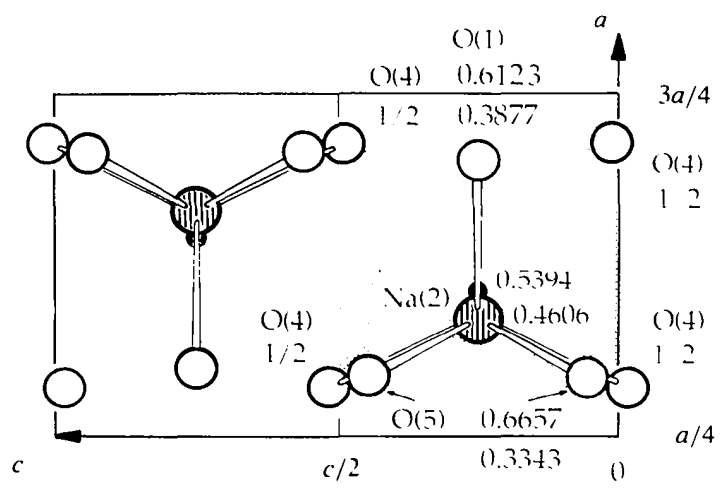

(b)

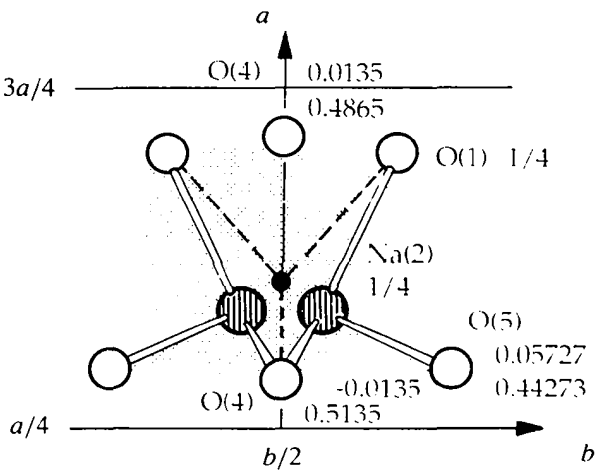

(c)

Fig. 4. Projections of the ten-membered cage surrounding $\mathrm{Na}(2)$ sites. Location of the proposed saddle point is indicated with a small dot. (a) Projection along $\mathbf{a} ;(b)$ projection along $\mathbf{b}$; $(c)$ projection along c. 
Table 4. Locations and nearest neighbors of proposed interstitial sites

Numbers in parentheses identify atoms in terms of Table $1.2 \times$ indicates multiplicity of the bond. Standard deviations are not given as sites are proposed and the positions have not been refined from X-ray data.

$\begin{array}{llllll}\text { Site } & \text { Coordinates } & \text { Neighbor } & \text { Distance } & \text { Neighbor } & \text { Distance } \\ 8 i . . m & 0.54,0.28, \frac{1}{2} & \mathrm{O}(1) & 1.981 & \mathrm{Si}(1) & 2.806 \\ & & \mathrm{O}(2) & 1.982 & \mathrm{O}(5) 2 \times & 2.813 \\ & & \mathrm{Na}(1) 2 \times & 2.235 & \mathrm{O}\left(5^{\prime}\right) 2 \times & 2.979 \\ 8 f .2 . & \frac{1}{2}, 0.41, \frac{1}{2} & \mathrm{O}(5) 2 \times & 2.119 & \mathrm{Si}(1) 2 \times & 2.340 \\ & & \mathrm{O}(4) 2 \times & 2.324 & \mathrm{Na}(2) 2 \times & 2.375 \\ & & \mathrm{O}(1) 2 \times & 2.654 & \mathrm{Na}(1) & 2.594\end{array}$

The second interstitial site at $8 f 2\left(\frac{1}{2}, 0.41, \frac{1}{2}\right)$, Table 4 , appears to be an even more favorable local minimum. All the four nearest neighbors to this site are $\mathrm{O}$ atoms, located at distances of 2.12 and $2.32 \AA$, almost ideal distances for a fourfold-coordinated sodium ion. In fact, only the presence of two Si atoms at distances of $2.34 \AA$ appear to make the site unsuitable for normal occupation. In addition to its favorable coordination polyhedra, the $8 f$ site is likely to be an integral part of a migration pathway, because of its accessibility from the normal sites. For example, migration from an $\mathrm{Na}(2)$ site might occur through the $\mathrm{O}(5)-\mathrm{O}(4)-\mathrm{O}\left(4^{\prime}\right)$ face of the tenmembered cage, or from an $\mathrm{Na}(1)$ site via the $\mathrm{O}(5)-\mathrm{O}\left(5^{\prime}\right)$ edge of the distorted octahedron.

In addition to the two proposed interstitial sites, vacancies also appear to result from the one-half occupancy of the $\mathrm{Na}(2)$ sites. However, the proximity of neighboring $\mathrm{Na}(2)$ sites, as noted above, suggests that simultaneous occupation is unlikely. This, in turn, implies that unoccupied $\mathrm{Na}(2)$ sites cannot serve as truly accessible vacancies to $\mathrm{Na}^{+}$ions moving from one cage to another. Alternatively, given the dimensions of the ten-cornered cage, it is quite likely that high concentrations of a divalent dopant such as $\mathrm{Ca}$ or $\mathrm{Sr}$ can be incorporated at this site to render the material an extrinsic conductor.

Although potential interstitial/vacant sites have been identified, there is certainly no proof that these sites truly represent local minima that are, at least, temporarily occupied. If, in fact, these interstitial sites are not energetically favorable and thus have extremely low occupancies, alkali-ion migration directly between normal sites would still remain a possibility. For example, an alkali ion might jump between $\mathrm{Na}(2)$ cages sites via the shared $\mathrm{O}(4)-\mathrm{O}\left(4^{\prime}\right)$ edge. As the midpoint of the edge is at $4 a .2 / \mathrm{m}$. $\left(\frac{1}{2}, \frac{1}{2}, \frac{1}{2}\right)$, a site of $\overline{1}$ symmetry, the $\mathrm{Na}^{+}$ion would be required to squeeze directly through the midpoint, or be able to pass at two locations along the edge related by inversion symmetry. The length of the $\mathrm{O}(4)-\mathrm{O}\left(4^{\prime}\right)$ edge is $3.755 \AA$, and, being somewhat smaller than twice the sum of the ionic radii of sodium and oxygen, suggests that a straight line path is the more probable of the two options. Following a path that leads around the $\mathrm{O}(4)-\mathrm{O}\left(4^{\prime}\right)$ edge, on the other hand, is essentially equivalent to utilizing the site earlier identified at the $8 f$ position.

The nature of the structure of a fast-ion conductor is such that the energy barriers to motion of the mobile species are very small and thus the mobile ion resides in a shallow potential well. This is commonly reflected in large thermal vibration parameters for the mobile ion, particularly along the direction of the diffusion jump. Table 1 shows the anisotropic temperature factor coefficients for $\mathrm{Na}(2)$ are indeed large. In particular, the value of $5.20 \times 10^{-2} \mathrm{~A}^{2}$ for $U_{22}$ further supports the notion of jumps along $b$ between adjacent sites within the ten-cornered cage. The value of $2.46 \times$ $10^{-2} \mathrm{~A}^{2}$ for $U_{33}$, approximately in the direction of the shared edge between neighboring cages, is the smallest of the diagonal elements, but is still of appreciable magnitude. The temperature factor coefficients for $\mathrm{Na}(1)$ are moderate, consistent with the shorter $\mathrm{Na}-\mathrm{O}$ bond distances, and indicate a smaller degree of anisotropy, consistent with the more even distribution of nearestneighbor anions. The anisotropy, nevertheless, reflects the distorted nature of the octahedron in that the largest thermal displacement occurs within the $a c$ plane and in a direction along which the arrangement of surrounding anions was noted to be more open.

To this point we have been unable to grow crystals large enough to perform conductivity measurements and thus confirm the presence of fast-ion conduction in the structure. Attempts to densify pressed pellets led to melting and the formation of a stable glass. It is hoped that the transport properties and their dependence on crystallographic direction can be determined from the synthesis of larger crystals, as done for phases encountered in the $\mathrm{K}_{2} \mathrm{O}-\mathrm{Nd}_{2} \mathrm{O}_{3}-\mathrm{SiO}_{2}$ system (Haile, Wuensch, Siegrist \& Laudise, 1992).

\section{Concluding remarks}

We have found that the structure of $\mathrm{Na}_{3} \mathrm{YSi}_{6} \mathrm{O}_{15}$ contains a silicate unit based on unique double dreier-rings. We have proposed that such a configuration, rather than the layered structures observed in the $\mathrm{Na}_{3} \mathrm{NdSi}_{6} \mathrm{O}_{15} \cdot x \mathrm{H}_{2} \mathrm{O}$ and $\mathrm{K}_{3} \mathrm{NdSi}_{6} \mathrm{O}_{15}$ analogs, is obtained because of the greater electronegativity of $\mathrm{Y}$ relative to $\mathrm{Nd}$, rather than the difference in size. In order to accommodate the small $\mathrm{Si}-\mathrm{O}-\mathrm{Si}$ angles which result from the double dreier-ring configuration, the $\mathrm{Si}-\mathrm{O}$ bond lengths in $\mathrm{Na}_{3} \mathrm{YSi}_{6} \mathrm{O}_{15}$ are unusually long. When taken together with the $\left(\mathrm{YO}_{6}\right)$ octahedra, the structure formed is a three-dimensional framework with channels along $\mathbf{c}$. The placement of $\mathrm{Na}^{+}$ions within these tunnels, the existence of potential interstitial sites and the nature of the polyhedral connectivity between these and the normal sites suggest easy ion migration and thus high intrinsicionic conductivity in the $c$ direction. Very high thermal vibration amplitudes are indeed observed for $\mathrm{Na}(2)$, often indicative of high-ionic mobility. However, the 
highest thermal displacements of this species occur along directions perpendicular to the proposed direction of motion, approximately towards the neighboring partially occupied site.

We are indebted to Dr Peter Höhn of the Max-PlanckInstitut für Festkörperforschung for providing singlecrystal intensity data and to Eva-Marie Peters for assistance with the structure determination. We thank Mike Jercinovic of the Massachusetts Institute for Technology for supplying microprobe analyses and Ortrud Buresch of the Max-Planck-Institut für Festkörperforschung for performing the plasma spectroscopy. $\mathrm{SH}$ is grateful to the AT\&T Cooperative Fellowship Program, the Fulbright Foundation and the Alexander von Humboldt Foundation for providing financial support at various stages of this research.

\section{References}

Frostäng, S., Grins, J. \& Nygren, M. (1988). Chem. Scr. 28, 107-110. GoOdenough, J. B., Hong, H. Y.-P. \& Kafalas, J. A. (1976). Mat. Res. Bull. 11, 203-220.

Gunawardane, R. P., Howte, R. A. \& Glasser, F. P. (1982). Acto Cryst. B38, 1405-1408.
HaIlE, S. M. (1992). PhD thesis. Massachusetts Institute of Technology, Cambridge, Massachusetts, USA.

Hame, S. M., Siegrist, T., Laudise, R. A. \& Wuensch, B. J. (1991). Mat. Res. Soc. Symp. Proc. 210, 645-651.

HaIle, S. M., Wuensch, B. J. \& Laudise, R. A. (1993). J. Cryst. Growth, 131, 373-386.

Haile, S. M., Wuensch, B. J., Siegrist, T. \& Laudise, R. A. (1992). Solid State Ionics, 53-56, 1292-1301.

Halle, S. M., Wuensch, B. J., Siegrist, T. \& Laudise, R. A. (1993). J. Cryst. Growth, 131, 352-372.

LAUDISE, R. A. (1987). In Advanced Crystal Growth, edited by P. M. Dryburgh, B. Cockayne \& K. G. Barraclough. New York: Prentice Hall.

Liebau, F. (1985). Structural Chemistry of Silicates: Structure, Bonding, and Classification. Berlin: Springer-Verlag.

Pushcharovskil, D. Y., Karpov, O. G., Pobedimskaya, E. A. \& Belov, N. V (1977). Sov. Phys. Dokl. 22, 292-293.

SChamber, F., Wodke, N. \& MCCARTHY, J. (1981). ZAF Matrix Correction Procedure for Bulk Samples: Operation and Program Description, 31pp. Tracor Northern Publication TN-2120, Middleton, Wisconsin, USA.

Shannon, R. D. \& Prewitt, C. T. (1969). Acta Cryst. B25, 925-946.

Shannon, R. D., Taylor, B. E., Gier, T. E., Chen, H.-Y. \& Berzins, T. (1978). Inorg. Chem. 17, 958-964.

SHELDRICK, G. M. (1985). Crystallographic Computing 3, edited by G. M. SHELDRICK, C. KRUGER \& R. GODDARD, pp. 175-189. Oxford Univ. Press.

SMolin, Y. I. (1970). Sov. Phys. Crystallogr. 15, 23-27.

TutTLE, O. F. (1949). Geol. Soc. Am. Bull. 60, 1927.

Watanabe, M. \& Wuensch, B. J. (1993). J. Solid State Chem. In the press.

Acta Cryst. (1995). B51, 680-687

\title{
Structure of $\mathrm{Cs}_{3}\left(\mathrm{HSO}_{4}\right)_{2}\left(\mathrm{H}_{2} \mathrm{PO}_{4}\right)$ - a New Compound with a Superprotonic Phase Transition
}

\author{
BY S. M. HAILE
}

Department of Materials Science and Engineering, Box 352120, University of Washington, Seattle, WA 98195, USA

AND K.-D. KREUER AND J. MAIER

Max-Planck-Institut für Festkörperforschung, 70569 Stuttgart, Heisenbergstrasse 1, Germany

(Received 15 February 1995; accepted 27 April 1995)

\begin{abstract}
Solid-solution studies in the $\mathrm{CsHSO}_{4}-\mathrm{CsH}_{2} \mathrm{PO}_{4}$ system carried out in a search for low-temperature proton conducting materials yielded the new compound $\mathrm{Cs}_{3}\left(\mathrm{HSO}_{4}\right)_{2}\left(\mathrm{H}_{2} \mathrm{PO}_{4}\right)$ [tricesium bis(hydrogensulfate) dihydrogenphosphate]. Single-crystal X-ray measurements (performed at room temperature) revealed that $\mathrm{Cs}_{3}\left(\mathrm{HSO}_{4}\right)_{2}\left(\mathrm{H}_{2} \mathrm{PO}_{4}\right)$ crystallizes in space group $P 2_{1} / n$ and has lattice parameters $a=19.546(3), b=$ $7.8798(10), c=9.1854(17) \AA$ and $\beta=100.536(14)^{\circ}$. With four formula units in the unit cell, and a cell volume of $1390.7(4) \AA^{3}, \mathrm{Cs}_{3}\left(\mathrm{HSO}_{4}\right)_{2}\left(\mathrm{H}_{2} \mathrm{PO}_{4}\right)$ has a calculated density of $3.295 \mathrm{Mg} \mathrm{m}^{-3}$. 18 non- $\mathrm{H}$ atoms were located in the asymmetric unit. Refinement using anisotropic temperature factors for all $18 \mathrm{non}-\mathrm{H}$ atoms
\end{abstract}

yielded weighted residuals based on $F^{2}$ and $F$ values, respectively, of 9.32 and $4.56 \%$ for all observed reflections. Hydrogen sites were identified (but not refined) on the basis of geometric considerations. The structure contains zigzag chains of hydrogen-bonded anion tetrahedra that are, in turn, bonded to one another to form a three-dimensional structure. In the temperature range $381-398 \mathrm{~K}$ the compound transforms into a structure which is rhombohedral, pseudo-body-centered cubic, with lattice constants $a=6.95$ (2) $\AA$ and $\alpha \simeq 90^{\circ}$.

\section{Introduction}

Many classes of solid acid sulfates and selenates are known to undergo superprotonic phase transitions 